\title{
CORRESPONDENCE
}

\begin{abstract}
Medical genetics
R Harris, FRCP.............. 574

Ear-piercing problems

Ann L Jay, MB ............. 57

Stress incontinence

D $\mathrm{H}$ Lees, FrCOG, and A Singer, MRCOG;

D M Essenhigh, FRCs............. 575

Shortage of anaesthetists

A W Fowler, FRCS; M Rosen, FFARCs . . . . . 576

Pinning down the diagnosis in breast cancer

C J Davies, FrCs, and others......... 576

Developmental screening

S J Carne, fRCGP............... 577

Vision screening in preschool children

P A Gardiner, MD . . . . . . . . . . . . . 577

Immersion and drowning in children

W J Guild, PHD............... 577

Oestrogen therapy and endometrial cancer

W H Utian, MD ................ 577

Depot tranquillisers for disturbed

behaviour

H G Kinnell, MrcP............... 578

Liver biopsy in "difficult" jaundice

I S Benjamin, FRCSGLAS, and others..... 578

Effect of abortion on obstetric patterns

A F Pentecost, fRCSED ............. 578

More hydatidiform moles?

J P Calvert, мв............ 578

Preventing prematurity in twins

A H A Wynn, MA............. 579

Campylobacter enteritis

Elizabeth I Tanner, FRCPATH, and $\mathrm{C} \mathrm{H}$ Bullin, FIMLT.

Plasma drug levels on once-daily dosage

I H Stevenson, MB, and A A Schiff, MRCs. . 579

Hygiene in NHS hospitals

G Aston, and $\mathrm{H}$ Gordon, $\mathrm{MFCM} . \ldots \ldots 579$

Training programmes

S Oleesky, FRCP............. 579

Megaloblastic anaemia associated with sulphasalazine treatment

R Schneider, FRCPED, and Linda Beeley,

MRCP...............................

demented patient

W Fine, FRCP, and D J Walker, MRCP.... 580

Acute suppurative thyroiditis caused by Pseudomonas aeruginosa

M Weissel, MD, and others.......... 580

Prolonged action of intramuscular

naloxone

M A McGuigan, MD, and A A Mitchell, MD 580

Management of vesicoureteric reflux in

children

G B McKelvie, FRCSED.

Correspondents are urged to write briefly so that readers may be offered as wide a selection of letters as possible. So many are being received that the omission of some is inevitable. Letters should be signed personally by all their authors.
\end{abstract}

Infantile acne

D Rowley-Jones, MRCP.......... 581

Renal lead excretion

B C Campbell, MRCP, and $\mathrm{H}$ L Elliott,

MRCP.................... 581

Danger of instant adhesives

I Picton-Robinson, MB ........... 581

Catatonic stupor responsive to ECT

M Silverman, FRCPSYCH........... 582

Carbon dioxide-dependent staphylococcus

A Beck, FRCPATH, and G Hounsome, FIMLS 582

Survival of specialist societies

E W B Varley, FDSRCS . . . . . . . . . . . 582

How many medical students?

J Bettinson, LLB . . . . . . . . . . . 582

GMSC and the Court Report

A Elliott, fRCGP............. 582

Industrial action

M J Gilkes, FRCs; G N W Tilsley, MB;

A Mary Duguid, MB; E G Cohen, MB;

A A F Sanderson, мB.......... 582

Points from letters Isolation units (I $M$ Librach; H G Easton); Athletes and atheroma (R C Orselli); Entry to medicine (P R J Vickers); Photo-onycholysis caused by tetracyclines (F R Bettley); Prednisolone for hay fever (J T

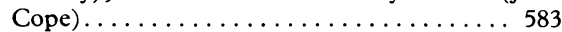

\section{Medical genetics}

SIR,-Your leading article on medical genetics (30 July, p 279) correctly emphasised the need for medically trained and active geneticists. I fear, however, that the prescription contained in your article is for a physician or paediatrician with interest in medical genetics rather than for the type of individual needed to take part in the running of the genetic service which most regions have already established. Clinical geneticists, cytogeneticists, biochemists, nurses, clerical staff, and others work together in these centres to provide patients and their families with adequate pre- and post-natal diagnostic counselling and follow-up services. The clinical geneticist has a central role in this team since he has some of the clinical responsibilities and acts as a link man between patients, general practitioners, and other consultants on the one hand and the specialised genetic services on the other. The clinical geneticis faced with patients who may have diseases of any system must know when and to whom to refer the patient for specialised diagnosis and management. In this respect he closely resembles the family practitioner, who has long recognised his responsibilities to all of his patients however obscure their diagnosis Like a GP he must remain flexible and resourceful, he must keep up to date over an enormous area, including rapidly evolving prenatal diagnostic techniques, and be able to assist in the diagnosis of rare syndromes. New discoveries are coming thick and fast and the genetic complexities of HLA and disease are correctly the province of the clinical geneticist, who should act as first-line interpreter between the serologist and other clinicians. New and useful forms of treatmen or diagnostic tests are imminent in at least a few of the following genetic diseases: Huntington's chorea, cystic fibrosis, and the muscular dystrophies.

The genetic team in each region will not of course, itself provide the full range of clinical, laboratory, social, and other services which will be necessary, but the clinical geneticist has an important duty in surveying what is available and attempting by direct participation, or by the encouragement of others, to remedy any deficiencies. The basic necessities include the provision of genetic counselling clinics and reliable cytogenetic and biochemical laboratories experienced in handling both ante- and post-natal material together with adequate back-up services including health visitors, social workers, and clerical staff.

Very few doctors practising today have had any real genetic training, but we must work towards the day when the majority of clinicians are competent to look after the genetic aspects of their own specialties. Clinical geneticists must play the leading part in postgraduate and undergraduate education in this area. In the meantime genetic counselling and referral for specialised genetic tests is not always done well in Britain and for some time to come clinical geneticists must play the largest part in seeing that the increasing and reasonable expectations of patients can be met by improving available services. Your leading article will encourage many young doctors to seek a greater specialist knowledge of clinical genetics and this is excellent. However, physicians with an interest in medical genetics but who had more than two or three general sessions would be hard pressed to play their full share as one of two or at most three clinical geneticists in the regional service. The memorandum on training medical geneticists which was submitted to the Joint Committee on Higher Medical Training by a working party from the Clinical Genetics Society has indicated very clearly indeed the optimum training of the small number of clinical geneticists that will be required in Britain.

RODNEY HARRIS

University Department of

Medical Genetics,

St Mary's
Manchester

\section{Ear-piercing problems}

SIR,-Twenty children were seen in this department between 19 January and 25 June 1977 with problems following piercing of the ears. Their notes were reviewed retrospectively.

All the children were girls aged 6-14 years, six of them being only 6 years old. In 12 cases part of the earring had become embedded in the ear lobe and five of these had superadded infection. Four patients had infection at the site of perforation. Three children had suffered trauma to the earlobe; in two cases this was deliberately inflicted by another child and in the third the ear was injured by the stud during a fall. One child developed a keloid scar at the 